\title{
The needs of different types of family in preschools in Taiwan
}

\author{
Shu-Jung Lin ${ }^{*}$, Sung-Ho Yang ${ }^{2}$ \\ ${ }^{1}$ Department of Early Childhood Education, Nanhua University, Chiayi, Taiwan \\ ${ }^{2}$ Chia Hwa Senior High School, Chiayi, Taiwan
}

\section{Keywords}

Single-parent families Dual-income families Skipped-generation families New-immigrant families

Received: 15 April 2016 Accepted: 11 June 2017 Published: 21 August 2017

\begin{abstract}
The purpose of this study was to clarify the needs of different types of families in Taiwan, have for preschools. Stratified random sampling was used to recruit 272 dual-income families, 154 single-parent families, 117 skipped-generation families, 142 new-immigrant families, and 62 others. The results indicate that single-parent families need "flexible services," the new-immigrant families need "various talents," the dual-income families need "life education" and "home-school relationship." These findings suggest that preschools that understand the differing needs of different family types will be better positioned to implement a program that gives due consideration to the education and welfare of the children themselves and satisfies the family's needs. It is expected that the results will help preschools set up learning environments which meet children's learning and needs of the different types of family.
\end{abstract}

(C) 2017 The Author(s). Published by TAF Publishing.

\section{INTRODUCTION}

Taiwanese society is in a state of flux. In terms of demographics, the most significant trend is the rapidly decreasing birthrate (the lowest in the world, according to statistics published in 2014 by the Population Reference Bureau in the US) and the resulting increase in the population of the elder (Ministry of the Interior, 2015a).

In recent decades, there has also been a steady increase in the number of women entering the workforce, dual-income families, single parent families, and the number of foreign brides (mainly from Southeast Asia and mainland China) (Hsu and Peng, 2006). All this is giving rise to an increasing number of non-traditional families.

Recent decades have also witnessed a steady increase in the number of marriages ending in divorce. According to statistics compiled by Taiwan's Ministry of the Interior (2015b) in 2000 there were 744,394 divorcees in Taiwan, and by 2014, this number had increased to $1,587,914$. One result of this dramatic rise in the divorce rate has been a corresponding increase in the number of single-parent families and skipped-generation families (families in which the grandparents raise children and parents are absent from the household).

In the wake of the far-reaching changes brought on in the West by the industrial revolution and the feminist movement during the 19th and 20th centuries, increasing numbers of women began to engage in paid employment, including after marriage and after childbirth. By 2000, most Europeans approved of women working outside the home, and in many Western European countries (Britain, France, Germany, Holland, Denmark, Portugal,

\footnotetext{
${ }^{*}$ Corresponding author: Shu-Jung Lin

${ }^{\dagger}$ Email: s0970815@gmail.com
} 
etc.), over 40 percent of adult women engaged in paid employment. Such developments raise some challenging questions regarding the upbringing and education of children in non-traditional families (Lu et al., 2015). The increasing diversity of families in Taiwan presents a considerable challenge to preschool administrators and teachers. Parents are often viewed as responsible decision-makers regarding early care and education (Cryer et al., 2002), then frequently parents have different standpoints and needs from preschools. In such a situation, preschools and their teachers need to actively strive to understand and meet the needs of non-traditional families.

Yet it remains to be seen to what extent they are actually taking steps in this direction. Most of the related studies which have appeared in recent years focus on the declining birthrate and recommend that preschools give this factor priority when adopting marketing strategies. Some of the strategies are commonly proposed by scholars of education (Hill and Jones, 1995; Kahraman, 2016; Porter, 1990; Tsai, 2007). However, such strategies are mainly formulated by preschool administrators who surmise the needs of parents and then have the teachers implement them, but they often miss the mark. Accurately ascertaining parental needs is the key point. It is expected that the results of this study can be contributed to the preschools to gain a better framework on the actual needs of the different types of family, and make necessary changes. Doing so will not only increase parental satisfaction and help to create a more wholesome learning environment for children, but will also help preschools survive and thrive in the competitive market of preschool education.

\section{LITERATURE REVIEW}

Single-Parent Families

According to Taiwan's Ministry of the Interior (2005), single-parent families spend a greater proportion of the family income on their children's education than other types of families do, a situation which only serves to exacerbate the already straightened financial situation of single parents. This is especially true of single mothers, for many of whom financial difficulties result in psycho-physical stress which has a negative impact on their ability to take care of themselves and their children (Christopher, 2004; Kaplan et al., 2005). Children raised in such a household often have more difficulties in their studies and adapting to the school environment (Kamaruddin and Sulaiman, 2017; Zhan and Sherraden, 2003). As a result, single parents tend to select preschools which are more flexible about the timing of bringing their children to school in the morning and picking them up in the afternoon; they also give more importance to the school's ability to provide day-care functions and help children adapt to the new environment (Duan, 2007; Pong, 2006).

\section{Skipped-Generation Families}

According to the results of a survey on family income and expenditures conducted by the Taiwan's Ministry of the Interior in 2006, the number of skipped-generation families had doubled since 1990, and 85 percent of the grandchildren in this type of family are minors. Furthermore, research indicates that skipped-generation families tend to suffer from a problematic generation gap and/or spoiled grandchildren, and that many grandparents need guidance when it comes to communicating with and raising grandchildren (Huang, 2003; Huang, 2004).

New Immigrant Families

According to the National Immigration Agency (2016), there were over 511,623 foreign spouses, most of whom were women from Southeast Asia and mainland China. Researchers 
have found that most of these foreign brides come from impoverished backgrounds, have a low level of formal education, and little knowledge of Chinese, many face serious difficulties in cultivating parent-children relationship and raising their children (Chen, 2010; Lin and Chou, 2011; Huang and Wan Peter, 2008). Moreover, the children of these newimmigrant families often fall behind at school, and thus require extra support and guidance (Wang, 2010).

\section{Dual-Income Families}

As for dual-income families, according to a report published by the Executive Yuan (2011), in 1979, over 40 percent of the married women in Taiwan had never engaged in paid employment, but by 2010, this figure had dropped to less than nine percent. The same report also states that after childbirth, around 90 percent of Taiwanese women reenter the workforce. The children of such families, now in the majority in Taiwan, also have special requirements.

Due to the demands of working outside the home, mothers in dual-income families have less time to spend with their children. Research has found that dual-income families in Taiwan have relatively higher needs for their children, and expect schools to train children to be independent. At the same time, although it might be expected that the steady increase in the number of dual-income families in Taiwan would lead to a corresponding demand for child-care services.

From the aforementioned literature, various types of family have different needs due to their real life situation. Therefore, teaching life education, supporting environmental facilities, flexible service, and various talents, also building a good home-school relationship are very important to enhance children's learning and content to the various patterns of family.

\section{RESEARCH METHODOLOGY Participants}

Stratified random sampling was used to conduct a survey of the participant children enrolled at preschools throughout Taiwan. Amongst the participating preschools, 33.5\% were public and $66.5 \%$ were private. The questionnaire was sent to 1,200 participants, and a total of 852 questionnaires were returned, 747 of which were found to be valid, amounting to a valid retrieval rate of $62.25 \%$. The public preschools accounted for $40.6 \%$ of the participants, while the private preschools accounted for $59.4 \%$. As for type of family structure, $36.4 \%$ were dual-income families, $20.6 \%$ were single-parent families, $15.7 \%$ were skipped-generation families, $19.0 \%$ were new-immigrant families, and $8.3 \%$ were others.

\section{Research Procedure and Tool}

Although similar questionnaires have been used in the past, since none of them differentiates between the different types of family structures, we created our own questionnaire titled "The Different Types of Family's Needs with Preschools". We first formulated a pilot questionnaire based on the results of interviews carried out during the first year of the study. We then gave the pilot version to four professors of early childhood education, three preschool directors, and four preschool teachers and asked them to evaluate the questions and rate their relative importance. Having received their feedback, we then carried out item analysis, factor analysis, and reliability analysis, based on the results of which we formulated the final version of the questionnaire. Using the procedures developed by Aiken, we determined that the questionnaire items had a mean validity coefficient 
of 0.86 , a mean homogeneity reliability coefficient of 0.79 , a total explained variance of $68.075 \%$, and a Cronbach's a of 0.929 , indicating that the questionnaire items had an acceptable level of reliability and validity.

Participants responded to items addressing their needs and with various needs of the preschools using a Likert scale on which ratings of 1-5 represented "extremely unneeded", "unneeded", "normal", "needed" and "extremely needed" respectively. Each response indicated the level of need experienced by respondents with regard to each preschool need. Higher scores represent higher levels of needs.

\section{Data Analysis}

The Statistical Package for the Social Sciences (SPSS) for Windows, Version 20.0, was used to compile and analyze the data. In addition to calculating the means and standard deviations of the participants' background data, a two-tailed $t$ test was used to compare the participants' public and private preschool differences in the needs. ANOVA was used to compare the four education groups and five family structure groups for the needs. Where significant differences were found, the Scheff é test was applied as a follow-up; $p<.05$ was accepted as significant.

\section{RESULTS}

The needs of different types of family in terms of the public and private preschool. From Table 1 it can be seen that there was a significant difference $(t=3.89, p<.05)$ between the participants' overall needs in terms of public and private preschool. Of the five domains, the participants of a public preschool had significantly higher needs for life education $(t=$ $5.54, p<.05)$, environmental facilities $(t=4.59, p<.05)$, and the home-school relationship $(t=3.48, p<.05)$.

TABLE 1. The needs of the participants in terms of the public and private preschools

\begin{tabular}{lllll}
\hline \hline Domain & Preschool & $M$ & $S D$ & $t$ \\
\hline Life education & Public & 35.77 & 3.56 & $5.54^{*}$ \\
& Private & 34.13 & 4.53 & \\
Environmental facilities & Public & 26.45 & 4.22 & \multirow{2}{*}{$4.59^{*}$} \\
& Private & 25.15 & 3.46 & \\
Flexible services & Public & 22.68 & 3.96 & -.19 \\
& Private & 22.73 & 3.73 & \\
Home-school relationship & Public & 20.12 & 4.24 & \multirow{2}{*}{$3.48^{*}$} \\
& Private & 19.22 & 2.87 & \\
Various talents & Public & 14.50 & 3.13 & \multirow{2}{*}{-.55} \\
& Private & 14.61 & 2.33 & \\
Overall & public & 119.52 & 12.03 & \multirow{2}{*}{$3.89^{*}$} \\
& Private & 115.85 & 13.11 & \\
\hline \hline
\end{tabular}

Note. ${ }^{*} p<.05$, Public $=303$, Private $=444$

\section{Needs in Terms of Family Structure}

Table 2 shows that there was a significant difference $(F=2.86, p<.05)$ between the participants' overall needs in terms of family structure. Furthermore, the post hoc test revealed that the single parents had higher overall needs than did the grandparents. Moreover, a significant difference was found for each individual domain. The post hoc test revealed that the single parents had higher needs for flexible services than did both the grandparents and the dual-income parents; and that the participants who belonged to a newimmigrant family had higher needs for various talents than did the dual-income parents. 
TABLE 2 . Needs in terms of family structure

\begin{tabular}{llllll}
\hline \hline Domain & Family Structure & $M$ & $S D$ & $F$ & Post Hoc Test \\
\hline Life education & A. Dual income & 35.35 & 4.17 & $3.15^{*}$ & ns \\
& B. Single parent & 34.91 & 4.17 & & \\
& C. Skipped generation & 33.96 & 4.59 & & \\
& D. New immigrant & 34.19 & 4.12 & & \\
Environmental facilities & E. Other & 35.03 & 4.01 & & \\
& A. Dual income & 25.97 & 3.28 & $3.24^{*}$ & ns \\
& B. Single parent & 26.23 & 5.35 & & \\
& C. Skipped generation & 24.82 & 3.63 & & \\
Flexible services & D. New immigrant & 25.21 & 3.13 & & \\
& E. Other & 25.69 & 3.14 & & \\
& A. Dual income & 22.03 & 3.79 & $7.13^{*}$ & B $>$ A,C \\
& B. Single parent & 23.92 & 3.76 & & \\
& C. Skipped generation & 22.20 & 4.18 & & \\
D. New immigrant & 23.12 & 3.54 & & \\
E. Other & 22.74 & 3.25 & & \\
Home-school relationship & A. Dual income & 19.96 & 4.42 & $2.40^{*}$ & ns \\
& B. Single parent & 19.62 & 2.96 & & \\
C. Skipped generation & 18.83 & 3.14 & & \\
D. New immigrant & 19.34 & 2.82 & & \\
E. Other & 19.84 & 1.98 & & \\
Various talents & A. Dual income & 14.17 & 2.60 & $3.44^{*}$ & D $>$ A \\
& B. Single parent & 14.83 & 2.64 & & \\
C. Skipped generation & 14.49 & 2.87 & & \\
D. New immigrant & 15.11 & 2.71 & & \\
E. Other & 14.58 & 2.48 & & \\
A. Dual income & 117.49 & 12.39 & $2.86^{*}$ & B >C \\
& B. Single parent & 119.51 & 13.21 & & \\
C. Skipped generation & 114.29 & 13.85 & & \\
D. New immigrant & 116.97 & 13.03 & & \\
E. Other & 117.89 & 9.83 & & \\
\hline \hline
\end{tabular}

$\overline{\text { Note. }{ }^{*} p<.05 ;{ }^{* *} p<.01 ; \text { n.s. indicates that no difference was found in the post hoc test. A = Dual income(272), } \mathrm{B}=\text { Sing }}$ le parent(154), C = Skipped generation(117), D = New immigrant (142), E = Other(62)

\section{DISCUSSION}

In this study it was found that, in comparison to the participants of children enrolled in private preschools, the participants of public preschools had higher needs for life education, environmental facilities, and the home-school relationship. These findings agree with the data obtained in the interviews conducted in the first year of this study, namely that parents need preschools to make up for areas in which they, as guardians are, deficient. This is especially the case for single-parent, skipped-generation, and new-immigrant families, the participants of which hope that the preschool will give much importance to life education and maintaining close contact with them. Most of the children enrolled in public preschools belong to disadvantaged families which fall into the categories of skipped generation, single parent, or new immigrant (Yang et al., 2012). Moreover, hoping to gain a competitive advantage over public preschools, private preschools typically give more importance to maintaining close contact with the participants, offering ample life education and guidance, and providing the best environmental facilities possible. Furthermore, 
private preschools tend to have longer preschool days, and are thus able to offer a more diverse array of talents. These are two important advantages of private preschools.

It was also found that the single parents gave more importance to flexible timing than did the grandparents and the dual-income parents. This agrees with Duan (2007) and Pong (2006), who found that single parents tend to prefer preschools which are more flexible about the timing of bringing their children to preschool in the morning and picking them up in the afternoon, and that they also give more importance to the preschools ability to provide day-care functions and help children adapt to the new environment. Moreover, single parents are more likely to have financial difficulties, predisposing them to psychophysical stress which has a negative impact on their ability to take care of themselves and their children. Children raised in such a household often have more difficulties in their studies and adapting to the school environment (Christopher, 2004; Kaplan et al., 2005).

As for the higher needs new-immigrant families have for various talents, as a number of studies (Chen, 2010; Huang and Wan Peter, 2008; Lin and Chou, 2011; Wang, 2010; Yildiz and Kayili, 2015) have pointed out, this is probably related to the fact that many such families are characterized by relatively low levels of education, socioeconomic status, and cultural capital. Add to this the significant language barriers hampering many new immigrants (especially those from Southeast Asia), and it's not surprising that the children of such families tend to have more difficulties at school. As a result, many new-immigrant families feel that even if their children do fall behind academically, they can still develop some kind of special talent which will help them make a good living. However, these same studies take a more practical view, and recommend that preschools provide various types of remedial education to help such children catch up with their classmates.

\section{CONCLUSION}

Preschools need to understand the needs of different types of families, and take these into account so as to provide reasonable services based on the educational objectives which balance academics, physical health, character building, and emotional maturity. For example, in light of the increasing number of non-traditional families, a preschool might want to recast the traditional observances of Mother's Day and Father's Day as something like "Most Important Person's Day", so that no child will feel excluded. Furthermore, life education at preschools needs to be better integrated into the overall curriculum to establish good daily life habits for children.

As for the physical environment, preschools need to give more importance to safety and replacing or discarding damaged or unused equipment. Finally, teachers need to take the initiative in maintaining contact with parents, so as to keep them up to date on their child's development and provide relevant information on education, childrearing, etc. Doing so makes parents feel that the teachers are solicitous about their child's welfare, and also gives teachers a chance to learn about and help out with any childrearing problems the parents may be having, to enhance home-school relationship. In sum, gaining an indepth understanding of the different types of family's needs is essential for a preschool's long-term success.

\section{LIMITATION AND RECOMMENDATIONS}

This study needs to provide respondents plural choices for filling the types of family for the purpose of matching the modern family pattern. Moreover, the types of family can be various according the literature review. Additionally, different cultures imply different stories which is worth to explore further the needs from various patterns of family of preschools. 


\section{ACKNOWLEDGEMENT}

We are grateful to the National Academy for Educational Research of Taiwan for the financial support in this study. We also are thankful to the research group, preschools, and participants.

\section{REFERENCES}

Chen, Stanley F. 2010. Classroom discourse analysis in the Kindergarten-Language learning of new immigrant children. Journal of National Taichung University 24, no. 2: 47-69.

Christopher, Karen. 2004. Welfare as we don't know it: A review and feminist critique of welfare reform research in the United States. Feminist Economics 10, no. 2: 143-171. DOI: 10.1080/135457004200217757

Cryer, Debby, Wolfgang Tietze, and Holger Wessels. 2002. Parents' perceptions of their children's child care: A cross-national comparison. Early Childhood Research Quarterly 17, no. 2: 259-277. D0I: 10.1016/S0885-2006(02)00148-5

Duan, Hong-Ying. 2007. The early childhood education policy and innovation with Taiwan's population structure changes. Journal of Educational Resources and Research 74: 57-72.

Executive Yuan. 2011. Labor statistic. URL: https://goo.gl/wnU6tP (accessed December 18, 2011).

Hill, Charles W., and Gareth R. Jones. 1995. Strategic management theory: An integrated approach. 3rd ed. Boston, MA: Houghton Miffin.

Hsu, Lung-An, and Chang-Cao Peng. 2006. The impact and implications of changing population characteristics on early childhood education. Journal of Child and Youth Welfare 10: 123-142.

Huang, Chi-Ying. 2003. The study on life adjustment of the 5th and 6th grade students in primary school from grand families in Northern Taiwan. Unpublished master's thesis, Chinese Culture University, Taipei, TW.

Huang, Stanley H., and Wan Peter H. 2008. A study on behavior puzzle and life adaption of new immigrant children in Hsinchu. Journal of Education and Foreign Language and Literature 7: 1-18.

Huang, Yang Hsien. 2004. The comparison of the ego-identity between the adolescence reared by grandparents and those reared by parents. Unpublished master's thesis, National Kaohsiung Normal University, Kaohsiung, TW.

Kaplan, George A., Kristine Siefert, Nalini Ranjit, Trivellore E. Raghunathan, Elizabeth A. Young, Diem Tran, Sandra Danziger, Susan Hudson, John W. Lynch, and Richard Tolman. 2005. The health of poor women under welfare reform. American Journal of Public Health 95, no. 7: 1252-1258. DOI: 10.2105/AJPH.2004.037804

Kahraman. 2016. Role of geography in environmental education. International Journal of Humanities, Arts and Social Sciences 2, no. 4: 121-125. DOI: 10.20469/ijhss.2.20001-4

Kamaruddin, Norfadilah, and Shahrunizam Sulaiman. 2017. A conceptual framework for effective learning engagement to- wards interface design of teaching aids within tertiary education. Journal of Advanced Research in Social Sciences and Humanities 2, no. 1: 35-42. DOI: 10.26500/jarssh-02-2017-0105

Lin, Sung-Jan and Yi-Hwa, C. 2011. The parenting education need of new immigrant children. Early Childhood Education 302: 43-51.

Lu, Chang-qin, Bei Wang, Oi-ling Siu, Luo Lu, and Dan-yang Du. 2015. Work-home interference and work values in greater China. Journal of Managerial Psychology 30, no. $7:$ 801-814.

Ministry of the Interior. 2005. The important indicators of the interior statistics. URL: https://goo.gl/up2C6 (accessed December 31, 2005).

Ministry of the Interior. 2015a. Analysis of the population structure by the end of 103. URL: https://goo.gl/YKB2jy (ac- cessed January 17, 2015).

Ministry of the Interior. 2015b. Population by marital status. URL: https://goo.gl/oUI3v (accessed January 19, 2015). National Immigration Agency. 2016. The number of foreign spouses and mainland (including Hong Kong and Macao).

URL: https://goo.gl/ZbHFWA (accessed March 18, 2016).

Pong, Sheng-Hong. 2006. The life situations of female-headed families. Soochow Journal of Social Work 14: 25-62.

Porter, Michael E. 1990. The competitive advantage of nation. New York, NY: The Free Express.

DOI: $10.1007 / 978-1-349-11336-1$

Tsai, Chia-Ti. 2007. Preschool innovative business strategies of declining birthrate era. Preschool Education 200, 10-15. 
Wang, Yi-Han. 2010. Being a mother in a foreign land: Perspectives of immigrant wives on mothering experiences in Taiwan. Taiwan Journal of Southeast Asian Studies 7, no. 1: 3-40.

Yang, Shi Cheng, Conrad C. Huang and Ian L. Huang. 2012. An integrated study about the impact of family transition on education of preschool (Report no.100-19). National Academy for Educational Research, Taipei, TW.

Ulku, Yildiz, and Gokhan Kayili. 2015. Examining the effects of computer-assisted preschool educational activities on children's intuitive mathematical ability. Journal of Advances in Humanities and Social Sciences 1, no. 1: 1-8.

DOI: 10.20474 /jahss1.1.1

Zhan, Min, and Michael Sherraden. 2003. Assets, expectations, and children's educational achievement in female-headed households. Social Service Review 77, no. 2: 191-211. D0I: 10.1086/373905

— This article does not have any appendix. - 